\title{
Baseline assessment of patient safety culture in public hospitals in Kuwait
}

\author{
Hayfaa Ali', Samaa Zenhom Ibrahem ${ }^{1,2}$, Buthaina Al Mudaf', Talal Al Fadalah', Diana Jamal ${ }^{3}$ and Fadi El-Jardali ${ }^{3^{*}}$ (D)
}

\begin{abstract}
Background: Conducting patient safety culture assessments can provide hospitals with information on how structures and processes within their system can impact patient outcomes. This study used the Hospital Survey on Patient Safety Culture (HSOPSC) to conduct an assessment of patient safety culture in public hospitals in Kuwait and benchmark against regional and international studies that utilized the same tool. This objective of this study is to examine the association between the predictors and outcomes of patient safety culture.

Methods: This cross sectional study adopted a customized version of HSOPSC developed by the Agency for Healthcare Research and Quality. The survey targeted selected public hospital staff with at least one year of experience. Data was analyzed using SPSS 24 at a significance level of 0.05 . Univariate analysis was utilized to obtain an overview of respondent demographics. The association between patient safety grade and the number of events reported and the remaining patient safety culture composites was analyzed using ANOVA f-test. Four regression models were constructed, two adopted Generalized Estimating Equations and the others were linear models. Results were benchmarked against similar initiatives in Lebanon, Saudi Arabia and USA.

Results: A total of 12,092 employees from 16 public hospitals in Kuwait completed the survey. The overall response rate was $60.5 \%$ (20,003 distributed surveys). Areas of strength were Teamwork within Units, Organizational Learning—Continuous Improvement, Management Support for Patient Safety, Supervisor/Manager Expectations \& Actions Promoting Patient Safety, and Feedback and Communication about Error. Regression findings highlighted significant association between patient safety outcomes and composites. Benchmarking analysis revealed that Kuwaiti hospitals are performing at or better than benchmark on several composites compared to regional and international findings.

Conclusion: This is the first major study addressing patient safety culture in public hospitals in Kuwait. Despite having some areas for improvement, public hospitals in Kuwait were found to have multiple areas of strength. Improving patient safety culture is critical if hospitals want to improve quality and safety of medical services. Study findings can guide and inform country level strategies to further improve the systems governing patient safety practices.
\end{abstract}

Keywords: Kuwait, Public hospitals, Baseline assessment, Benchmark, Hospital survey on patient safety culture

\section{Background}

Patient safety culture reflect the values that members of the organization share regarding what is important, how things operate and how inter-departmental interactions, structures and systems are collectively manifested in behavioural norms that support patient safety [1]. It reflects a non-punitive organizational culture that

\footnotetext{
*Correspondence: fe08@aub.edu.lb

${ }^{3}$ Department of Health Management and Policy, Faculty of Heath Sciences,

American University of Beirut, Beirut, Lebanon

Full list of author information is available at the end of the article
}

encourages reporting, analysing and learning from medical errors [2]. Ever since the Institute of Medicine (IOM) recommended a patient safety culture for building safety into the processes of care [2], evidence has been accumulating on the importance of cultivating patient safety culture to reduce adverse events and improve patient safety.

Conducting an assessment of patient safety culture in hospitals is only the first step of defining and refining a solid safety culture [3]. Multiple international accreditation 
organizations have now require patient safety culture assessments within their standards so that hospitals can assess and evaluate issues such as teamwork, managerial actions, support from upper administration and leadership to support patient safety, staffing challenges, reporting of incidents, and other related issues [4]. This allows healthcare organizations to develop a clearer view of the areas where they need to focus their attention as part of their efforts to strengthen patient safety culture [5]. Furthermore, when hospitals conduct such assessments, they can also benchmark their results against similar initiatives conducted within their country or at an international level [6].

Before we embark onto developing and improving patient safety culture we must first diagnose its current state and patient safety culture surveys are pivotal to assess areas of strengths and weaknesses in patient safety culture. The most commonly used patient safety culture survey is the Hospital Survey on Patient Safety Culture (HSOPSC) which assesses patient safety culture based on 12 dimensions: Teamwork within Units, Supervisor/ manager Expectations and Actions Promoting Patient Safety, Organizational Learning and Continuous Improvement, Management Support for Patient Safety, Overall Perceptions of Patient Safety, Feedback and Communication about Error, Communication Openness, Frequency of Events Reported, Teamwork across Units, Handoffs and Transitions, Staffing and Non punitive Response to Error [7]. The HSOPSC survey, which was developed by the Agency for Healthcare Research and Quality (AHRQ), has immense international reverberation as it has been validated and used in different continents and contexts [8].

Multiple studies and systematic reviews have tackled the issue of patient safety culture in the Arab world and beyond. A systematic review targeting Arab countries identified non-punitive response to error as a major challenge and healthcare professionals in these countries reported that culture of blame prevents them from reporting incidents [9]. Challenges pertaining to nonpunitive response to error were also highlighted in Swedish hospitals [10], Tunisian operating rooms [11], and Iran [12]. Focusing on improving response to error is crucial to improving error reporting and in fact, the likelihood of voluntary incident reporting was found to improve by focusing efforts on cultural changes such as improving event feedback mechanisms and communication of event-related improvements [13]. Evidence has shown that feedback can positively stimulate improvement in patient safety culture if it is tailored to specific departments and if outcomes were comprehensible for intended users [14]. Other areas requiring improvement were also highlighted in related evidence. They included Teamwork across Units, Handoffs and Transitions, Staffing and Communication Openness [15].
Many areas of strength were also highlighted in the patient safety culture literature whereby a study in Iran found that organizational learning-continuous improvement, teamwork within hospital units, and hospital management support for patient safety were all areas of strength [12]. Moreover, teamwork within units was better than teamwork across hospital units in Arab countries [9]. When assessing findings in specific countries, areas of strength in Lebanese hospitals were mainly related to Teamwork within Units, Management Support for Patient Safety, and Organizational Learning and Continuous Improvement [15]. As for KSA, and specifically Riyadh, areas of strength related to Organizational Learning and Continuous Improvement and Teamwork within units [16].

Predictors of a strong and positive patient safety culture include communication, ensuring flow of information between and across units, sharing a common vision on patient safety, in addition to commitment from management and leadership, and a non-punitive outlook towards incident reporting [17]. Investing in patient safety culture and quality management systems has been highlighted in recent studies in the Arab world [11]. Improving patient safety culture may also indirectly improve consumer-focused publicly reported hospital rating scores [18].

Limited research was found in the context of Kuwait. One study focusing on patient safety culture in primary care settings identified non - punitive response to errors, frequency of event reporting, staffing, communication openness, and handoffs and transitions as areas of weakness. Areas of strength were identified as teamwork within units and organizational learning [19]. This study, however, used the hospital survey for primary care settings, a tool specific to medical offices is available on the AHRQ website. No other studies focusing on patient safety culture in Kuwait were identified.

\section{Objectives}

The study aimed at assessing patient safety culture in public hospitals in Kuwait as perceived by hospital staff and compare results to those of similar regional and international studies. Furthermore, the study explored the association between patient safety culture predictors and outcomes, taking into consideration respondent characteristics.

\section{Methods}

This cross sectional study utilized the Hospital Survey on Patient Safety Culture (HSOPSC) developed by the Agency for Healthcare Research and Quality. The survey has been customized to fit the context of Kuwait. 


\section{Setting}

The survey covered 16 public hospitals in Kuwait; two of the hospitals were small-sized ( $<100$ beds), another two were medium-sized (101-300 beds), and the remaining 12 hospitals were large (more than 300 beds). There are 20 public hospitals in Kuwait, however, we selected 16 hospitals as the remaining facilities had only recently been established and as such did not meet our inclusion criteria as detailed below.

\section{Sampling and data collection}

The survey targeted selected hospital staff including physicians, nurses, pharmacy and laboratory staff, dietary and radiology staff, supervisors, and hospital managers. Data collection spanned 8 months (April to November 2015). Healthcare providers in the below mentioned categories were included in the study:

- Healthcare organization leaders (Hospital Director, Deputy Director, Assistant director).

- Heads of administrative departments (Social Services, Public Relations, Medical Records, Hotel Services, Accounting Services, Engineering, inventory, etc.).

- Physicians of all specialties and ranks (including those working in radiology, laboratory, nuclear medicine, etc.)

- Pharmacists

- Nurses

- Dieticians

- Infection control physicians and nurses including sterilization department staff.

- Quality physicians and nurses

- Physical, occupational, and speech therapist/ technicians

- Technicians (sterilization, lab, radiology, anaesthesia, pharmacy etc.)

- Medical engineering staff

- Medical records staff

\section{Exclusion criteria:}

- Staff on administrative or extended sick leave,

- Staff who have moved to another hospital area/unit, and

- Staff with less than 1 year of experience in the hospital.

Surveys were distributed through an assigned focal person at every hospital. A pre-determined number of surveys were sent to each hospital based on the total number of eligible employees. The surveys were coded with two numbers, one representing the hospital and the other representing the survey. Focal people were asked not to make copies of the survey so as not to jeopardize the integrity of the coding scheme determined by the research team. Surveys were distributed during department meetings or via departmental secretaries. Respondents were asked to refrain from writing their names or any information that would identify them on any page of the survey but they were asked to sign the consent form to verify that they read the information provided in it. They were asked to complete the survey and enclose it in a provided envelope, seal the envelope and return to a confidential drop box within each department.

\section{Study instrument}

The HSOPSC survey was utilized. The tool was translated to Arabic to account for employees who are not very comfortable with English. The Arabic version of the survey was adapted from El-Jardali et al. [15, 20].

Pilot testing was conducted with 20 employees who did not participate in the consequent phases of the study. Minor changes were made to the wording and categories within some questions as a result of piloting.

\section{Ethical approval}

Ethical clearance to conduct the survey was provided by the Standing Committee for Coordination of Health and Medical Research in Kuwait.

\section{Data management and analysis}

Data was analyzed using SPSS $24.0(p$-value $=0.05)$. The survey tool includes 42 items which measure 12 composites. The items are both positively and negatively wordedwhich are scored using a five-point scale reflecting respondent agreement/frequency (including a neutral category). Percent positive response within each composite was calculated. Negatively worded items were reversed prior to calculation of percent positive per composite. The full calculation method has been mentioned in El-Jardali et al. [15, 20] Internal consistency was calculated using Cronbach's alpha.

The survey has a total of 4 outcome variables. The first two are frequency of events reported and overall perception of safety which are measured within the 12 composites [7]. The remaining two outcome variables are the patient safety grade and the number of events reported which are measured as separate multiple choice questions [7].

Bi-variate analysis included $\boldsymbol{A N O} \boldsymbol{V A}$ f-test was used to examine the association between the two outcome variables with the patient safety culture composites. Student T-Test and ANOVA f-test were then used to examine how trends in the outcome variables differ across hospital and respondent characteristics. 
The four outcome variables were regressed against the 10 composite scores, respondent and hospital characteristics. Four regression models were constructed, two adopted Generalized Estimating Equations (the two categorical outcome variables: number of events reported and patient safety grade) and the other two models followed a Linear Mixed Regression Model (the two composites for frequency of events reported and overall perception of safety). In the latter models, the independent variables were entered as dummy variables. The two categorical outcomes were recoded into fewer categories for the purpose of this analysis. The outcome on patient safety grade was recoded into three categories "Poor or Failing," "Acceptable," and "Excellent/Good." The outcome on number of events reported was recoded into "> 5 events reported," "1 to 5 events reported," and "No events reported."

Results from the 16 participating hospitals were also benchmarked against similar initiatives in the United States (US) [21] and Lebanon [20]. Comparison to the benchmark value was done using the below formula [7]:

\%Distance from benchmark $=(($ benchmark value hospital result)/benchmark value) $* 100$

Values below $10 \%$ were categorized as meeting or exceeding benchmark. Those between 10 and 50\% were categorized as slightly deviating from benchmark. Those exceeding 50\% were categorized as highly deviating from benchmark.

\section{Results}

A total of 12,871 employees from 16 public hospitals in Kuwait completed the patient safety culture survey. However, some hospitals sampled respondents with less than 1 year of experience, and as such these 779 responses were removed from the dataset giving a total of 12,092 surveys. The overall response rate based on the final 12,092 surveys was $60.5 \%$ (20,003 distributed surveys).

\section{Demographics}

The majority of the sampled respondents were female (71.4\%) and most were found to hold a university level degree (72.3\%). Most of the sampled respondents were found to be nurses $(66.8 \%)$, while $11.9 \%$ were physicians and $11.5 \%$ technicians. The majority of respondents (91.6\%) indicated having patient interaction. Moreover, $86.4 \%$ were non-Kuwaiti. Finally, the majority of respondents worked in large hospitals (94.4\%) while 3.2\% worked in small hospitals and $2.4 \%$ worked in medium hospitals (See Table 1).

\section{Areas of strengths and areas requiring improvement} The twelve dimensions were examined to determine areas of strength (those with a positive rating of $70 \%$
Table 1 Demographic characteristics of sample

\begin{tabular}{|c|c|c|}
\hline & Number & Percent \\
\hline \multicolumn{3}{|l|}{ Gender } \\
\hline Male & 3406 & 28.6 \\
\hline Female & 8508 & 71.4 \\
\hline \multicolumn{3}{|l|}{ Education } \\
\hline High school or below & 572 & 4.8 \\
\hline University & 8551 & 72.3 \\
\hline Technical & 2573 & 21.7 \\
\hline Other & 137 & 1.2 \\
\hline \multicolumn{3}{|l|}{ Profession } \\
\hline Physician & 1425 & 11.9 \\
\hline Pharmacist & 283 & 2.4 \\
\hline Nurse & 7987 & 66.8 \\
\hline Physiotherapist & 434 & 3.6 \\
\hline Technician & 1381 & 11.5 \\
\hline Nutritionist/Dietician & 84 & 0.7 \\
\hline Administration & 121 & 1 \\
\hline Medical Records & 191 & 1.6 \\
\hline Others & 56 & 0.5 \\
\hline \multicolumn{3}{|l|}{ Experience in Hospital } \\
\hline Physician & 1425 & 11.9 \\
\hline Pharmacist & 283 & 2.4 \\
\hline Nurse & 7987 & 66.8 \\
\hline Physiotherapist & 434 & 3.6 \\
\hline Technician & 1381 & 11.5 \\
\hline Nutritionist/Dietician & 84 & 0.7 \\
\hline Administration & 121 & 1 \\
\hline Medical Records & 191 & 1.6 \\
\hline Others & 56 & 0.5 \\
\hline \multicolumn{3}{|l|}{ Interaction with patients } \\
\hline Yes & 10,838 & 91.6 \\
\hline No & 993 & 8.4 \\
\hline \multicolumn{3}{|l|}{ Nationality } \\
\hline Kuwaiti & 1609 & 13.6 \\
\hline Non-Kuwaiti & 10,255 & 86.4 \\
\hline
\end{tabular}

or higher) and those requiring improvement (scoring below $70 \%$ ) [22].

The dimensions with the highest positive score and are thus considered areas of strength were Teamwork within Units (89.7\%), Organizational Learning-Continuous Improvement (86.1\%), Management Support for Patient Safety (77.8\%), Supervisor/Manager Expectations \& Actions Promoting Patient Safety (77.1\%), and Feedback and Communication about Error (70.7\%). The remaining seven dimensions can be considered areas requiring improvement, they are teamwork across units 
(64.1\%), handoffs and transitions (62.2\%), overall perception of patient safety $(60.6 \%)$, frequency of events reported (59.0\%), communication openness (46.9\%), staffing (39.9\%) and non-punitive response to error (27.7\%) (Table 2).

Items considered areas of strength and others which require improvement were examined. The biggest area of strength highlighted by the responses was the item related to the hospital taking action to improve patient safety to which percent positive response was $95.1 \%$. Other areas of strength were revealed within the dimension on Teamwork within units whereby the item on whether staff support one another within a unit received 94.9\% positive responses, working together as a team when a lot of work needs to be done quickly $(93.1 \%$ positive) and treating each other with respect within the unit (90.9\% positive) (See Table 2).

The area with the lowest percent positive related to the dimension on non-punitive response to error whereby staff worry that their mistakes are kept in their personnel files (15.6\% positive, reverse item). Another item within this dimension that was found to be an area requiring improvement related to staff feeling their mistakes are held against them (29.5\% positive, reverse item). The dimension on staffing also emerged as problematic as staff indicated trying to do too much too quickly when working in crisis mode (18.5\% positive, reverse item). Moreover, $27.6 \%$ of responses indicate that staff work longer hours than is best for patient safety (reverse item). The dimension relating to communication openness was also found to be an area requiring improvement where only $30.0 \%$ of the staff feel free to question the decisions or actions of those with more authority and $43.1 \%$ only are not afraid to ask questions when something does not seem right (reverse item).

Results on areas of strength and areas requiring improvement are fully detailed in Table 2 .

\section{Association between patient safety grade and number of events with composites}

Respondents who gave "Excellent/Very Good" patient safety grades had significantly the highest mean scores for patient safety composites (See Table 3). Teamwork within Hospital Units and Organizational LearningContinuous Improvement demonstrated the highest mean score in relation to patient safety grade, while the Non-punitive Response to Error and staffing scored the lowest in relation to patient safety grade. The number of events reported was significantly associated with all of the patient safety composites. The highest mean observed when reporting more than 5 events was for the composite measuring Teamwork within Hospital Units while the lowest was observed for Non-punitive Response to Error (Table 3).

\section{Generalized estimating equations}

As detailed below, a one unit increase on composites relating to Supervisor/Manager Expectations \& Actions Promoting Patient Safety, Organizational learning and Continuous Improvement, Teamwork within units, Communication Openness, Feedback and Communications about Error, Staffing, Hospital Management Support for Patient Safety, and Teamwork across Hospital Units resulted in higher odds of reporting better patient safety grades. Similarly, a one unit increase on composites relating to Organizational learning and Continuous Improvement and Feedback and Communications about Error resulted in greater odds of reporting higher number of events while a one unit increase on Staffing and Hospital Management Support for Patient Safety resulted in lower odds of reporting number of events (Table 4).

Respondents holding a university degree were less likely to report better patient safety grades than those holding "other" degrees. Physicians, pharmacists, nurses and administrative staff, all had lower odds of reporting higher number of events compared to "other staff". Kuwaiti nationals had lower odds of reporting better patient safety grade but higher odds of reporting higher number of events compared to non-nationals. Respondents who had contact with patients had lower odds of reporting higher number of events compared to respondents with no patient contact. Respondents were more likely to report better patient safety grade as hospital size increased from small to medium. The opposite was observed for number of events where odds of reporting higher number of events decreased with increasing hospital size (Table 4).

\section{Linear mixed model regression}

The Linear regression analysis in Table 5 showed that a one unit increase in the scores on Organizational learning and Continuous Improvement, Feedback and Communications about Error, Hospital Management Support for Patient Safety and Hospital Handoffs \& Transitions resulted in higher frequency of events reporting. Similarly, a one unit increase in the scores on Supervisor/ Manager Expectations \& Actions Promoting Patient Safety, Organizational learning and Continuous Improvement, Teamwork within units, Communication Openness, Non-punitive Response to Error, Staffing, Hospital Management Support for Patient Safety and Hospital Handoffs \& Transitions resulted in a higher perceived patient safety. However, a one unit increase on Teamwork across Hospital Units resulted in a lower perceived patient safety (Table 5).

Male respondents were more likely to report lower frequency of events but more like to report a higher perceived patient safety. Respondents holding university 
Table 2 Percent positive per item and per subscale

\begin{tabular}{|c|c|c|c|}
\hline & $\%$ Positive & $\%$ Neutral & $\%$ Negative \\
\hline \multicolumn{4}{|l|}{ 1. Teamwork Within Units } \\
\hline People support one another in this unit. (A1) & 94.9 & 2.9 & 2.2 \\
\hline $\begin{array}{l}\text { When a lot of work needs to be done quickly, we work together as a team to } \\
\text { get the work done. (A3) }\end{array}$ & 93.1 & 4.1 & 2.9 \\
\hline In this unit, people treat each other with respect. (A4) & 90.9 & 6.1 & 3.1 \\
\hline When one area in this unit gets really busy, others help out. (A11) & 79.9 & 8.8 & 11.3 \\
\hline Average Teamwork Within Units & 89.7 & 5.5 & 4.9 \\
\hline \multicolumn{4}{|l|}{ 2. Supervisor/Manager Expectations \& Actions Promoting Patient Safety } \\
\hline $\begin{array}{l}\text { My supervisor/manager says a good word when he/she sees a job done according } \\
\text { to established patient safety procedures. (B1) }\end{array}$ & 80.4 & 11.3 & 8.2 \\
\hline $\begin{array}{l}\text { My supervisor/manager seriously considers staff suggestions for improving } \\
\text { patient safety. (B2) }\end{array}$ & 83.9 & 10.0 & 6.1 \\
\hline $\begin{array}{l}\text { Whenever pressure builds up, my supervisor/manager wants us to work faster, } \\
\text { even if it means taking shortcuts. (B3R) }\end{array}$ & 61.3 & 17.5 & 21.2 \\
\hline My supervisor/manager overlooks patient safety problems that happen over and over. (B4R) & 82.6 & 8.0 & 9.4 \\
\hline Average Supervisor/Manager Expectations \& Actions Promoting Patient Safety & 77.1 & 11.7 & 11.2 \\
\hline \multicolumn{4}{|l|}{ 3. Organizational Learning—Continuous Improvement } \\
\hline We are actively doing things to improve patient safety. (A6) & 95.1 & 3.1 & 1.8 \\
\hline Mistakes have led to positive changes here. (A9) & 76.0 & 14.1 & 9.9 \\
\hline After we make changes to improve patient safety, we evaluate their effectiveness. (A13) & 87.2 & 8.0 & 4.7 \\
\hline Average Organizational Learning_Continuous Improvement & 86.1 & 8.4 & 5.5 \\
\hline \multicolumn{4}{|l|}{ 4. Management Support for Patient Safety } \\
\hline Hospital management provides a work climate that promotes patient safety. (F1) & 81.3 & 10.4 & 8.3 \\
\hline The actions of hospital management show that patient safety is a top priority. (F8) & 86.1 & 8.5 & 5.4 \\
\hline $\begin{array}{l}\text { Hospital management seems interested in patient safety only after an adverse } \\
\text { event happens. (F9R) }\end{array}$ & 65.9 & 13.7 & 20.4 \\
\hline Average Management Support for Patient Safety & 77.8 & 10.9 & 11.4 \\
\hline \multicolumn{4}{|l|}{ 5. Overall Perceptions of Patient Safety } \\
\hline It is just by chance that more serious mistakes don't happen around here. (A10R) & 36.2 & 15.1 & 48.6 \\
\hline Patient safety is never sacrificed to get more work done. (A15) & 79.7 & 6.1 & 14.3 \\
\hline We have patient safety problems in this unit. (A17R) & 45.2 & 15.6 & 39.2 \\
\hline Our procedures and systems are good at preventing errors from happening. (A18) & 81.1 & 10.6 & 8.2 \\
\hline Average Overall Perceptions of Patient Safety & 60.6 & 11.9 & 27.6 \\
\hline \multicolumn{4}{|l|}{ 6. Feedback and Communication About Error } \\
\hline We are given feedback about changes put into place based on event reports. (C1) & 50.8 & 29.6 & 19.6 \\
\hline We are informed about errors that happen in this unit. (C3) & 79.9 & 14.1 & 6.1 \\
\hline In this unit, we discuss ways to prevent errors from happening again. (C5) & 81.5 & 12.7 & 5.8 \\
\hline Average Feedback and Communication About Error & 70.7 & 18.8 & 10.5 \\
\hline \multicolumn{4}{|l|}{ 7. Communication Openness } \\
\hline Staff will freely speak up if they see something that may negatively affect patient care. (C2) & 67.7 & 20.7 & 11.6 \\
\hline Staff feel free to question the decisions or actions of those with more authority. (C4) & 30.0 & 28.3 & 41.7 \\
\hline Staff are afraid to ask questions when something does not seem right. (C6R) & 43.1 & 36.7 & 20.2 \\
\hline Average Communication Openness & 46.9 & 28.6 & 24.5 \\
\hline \multicolumn{4}{|l|}{ 8. Frequency of Events Reported } \\
\hline $\begin{array}{l}\text { When a mistake is made, but is caught and corrected before affecting the patient, } \\
\text { how often is this reported? (D1) }\end{array}$ & 55.5 & 20.4 & 24.1 \\
\hline
\end{tabular}


Table 2 Percent positive per item and per subscale* (Continued)

\begin{tabular}{|c|c|c|c|}
\hline & \% Positive & $\%$ Neutral & $\%$ Negative \\
\hline When a mistake is made, but has no potential to harm the patient, how often is this reported? (D2) & 54.7 & 21.7 & 23.6 \\
\hline When a mistake is made that could harm the patient, but does not, how often is this reported? (D3) & 66.9 & 14.3 & 18.8 \\
\hline Average Frequency of Events Reported & 59.0 & 18.8 & 22.2 \\
\hline \multicolumn{4}{|l|}{ 9. Teamwork Across Units } \\
\hline Hospital units do not coordinate well with each other. (F2R) & 55.9 & 16.5 & 27.7 \\
\hline There is good cooperation among hospital units that need to work together. (F4) & 71.1 & 15.6 & 13.3 \\
\hline It is often unpleasant to work with staff from other hospital units. (F6R) & 46.3 & 21.1 & 32.6 \\
\hline Hospital units work well together to provide the best care for patients. (F10) & 82.9 & 10.7 & 6.4 \\
\hline Average Teamwork Across Units & 64.1 & 16.0 & 20.0 \\
\hline \multicolumn{4}{|l|}{ 10. Staffing } \\
\hline We have enough staff to handle the workload. (A2) & 60.8 & 11.9 & 27.3 \\
\hline Staff in this unit work longer hours than is best for patient care. (A5R) & 27.6 & 16.7 & 55.7 \\
\hline We use more agency/temporary staff than is best for patient care. (A7R) & 52.5 & 19.5 & 27.9 \\
\hline We work in "crisis mode" trying to do too much, too quickly. (A14R) & 18.5 & 13.8 & 67.7 \\
\hline Average Staffing & 39.9 & 15.5 & 44.7 \\
\hline \multicolumn{4}{|l|}{ 11. Handoffs \& Transitions } \\
\hline Things "fall between the cracks" when transferring patients from one unit to another. (F3R) & 54.6 & 18.7 & 26.7 \\
\hline Important patient care information is often lost during shift changes. (F5R) & 75.5 & 12.5 & 12.1 \\
\hline Problems often occur in the exchange of information across hospital units. (F7R) & 48.5 & 24.2 & 27.3 \\
\hline Shift changes are problematic for patients in this hospital. (F11R) & 70.3 & 15.5 & 14.2 \\
\hline Average Handoffs \& Transitions & 62.2 & 17.7 & 20.1 \\
\hline \multicolumn{4}{|l|}{ 12. Non-punitive Response to Error } \\
\hline Staff feel like their mistakes are held against them. (A8R) & 29.5 & 19.5 & 50.9 \\
\hline When an event is reported, it feels like the person is being written up, not the problem. (A12R) & 38.1 & 18.4 & 43.4 \\
\hline Staff worry that mistakes they make are kept in their personnel file. (A16R) & 15.6 & 13.7 & 70.8 \\
\hline Average Non-punitive Response to Error & 27.7 & 17.2 & 55.0 \\
\hline
\end{tabular}

"the composite-level percentage of positive responses was calculated using the following formula: (number of positive responses to the items in the composite/ total number of responses to the items (positive, neutral, and negative) in the composite (excluding missing responses))*100 (R) Negatively worded items that were reverse coded

degrees were more likely to report higher frequency of events. As for perception of patient safety, respondents holding university and technical degree were both more likely to report better perception. Nurses and Medical Records staff were more likely to report a lower frequency of events. Kuwaiti nationals were less like to report higher number of events but more likely to report a higher perceived patient safety grade (Table 5 ).

\section{Benchmarking}

In Table 6, the results are compared to the US benchmark. This benchmark was selected since it is the most recent (2013-2014) and reflects the results of a nationwide survey. Results are also compared to national surveys from Lebanon [15] and KSA [16]. Kuwait results were at or better than US benchmark for the seven composites: Teamwork within units, Supervisor/manager expectations and actions promoting patient safety,
Organizational learning-continuous improvement, Management Support for Patient Safety, Overall perception of patient safety, Feedback and communication about error, Teamwork across hospital units, and Hospital handoffs and transitions. Kuwait had composites scores that were at or better than benchmark for Lebanon for eight of the composites: Teamwork within units, Supervisor/manager expectations and actions promoting patient safety, Organizational learning-continuous improvement, Management Support for Patient Safety, Feedback and communication about error, Teamwork across hospital units, Staffing and Hospital handoffs and transitions. When compared with KSA, Kuwait results were at or better than benchmark for nine of the composites: Teamwork within units, Supervisor/manager expectations and actions promoting patient safety, Organizational learning-continuous improvement, Management Support for Patient Safety, Overall perception 
Table 3 Comparison between patient safety grade and number of events reported with patient safety culture composite scores (composites scored range from 1 to 5)

\begin{tabular}{|c|c|c|c|c|c|c|c|c|}
\hline & \multicolumn{4}{|c|}{ Patient Safety Grade } & \multicolumn{4}{|c|}{ Number of Events Reported } \\
\hline & \multirow[t]{2}{*}{ Sig. } & \multirow{2}{*}{$\begin{array}{l}\text { Poor or } \\
\text { Failing } \\
\text { Mean (SD) }\end{array}$} & \multirow{2}{*}{$\begin{array}{l}\text { Acceptable } \\
\text { Mean (SD) }\end{array}$} & \multirow{2}{*}{$\begin{array}{l}\text { Excellent/ Very } \\
\text { Good } \\
\text { Mean (SD) }\end{array}$} & \multirow[t]{2}{*}{ Sig. } & \multirow{2}{*}{$\begin{array}{l}\text { No event } \\
\text { reports } \\
\text { Mean (SD) }\end{array}$} & \multirow{2}{*}{$\begin{array}{l}1 \text { to } 5 \text { event } \\
\text { reports } \\
\text { Mean (SD) }\end{array}$} & \multirow{2}{*}{$\begin{array}{l}>5 \text { events } \\
\text { reported } \\
\text { Mean (SD) }\end{array}$} \\
\hline & & & & & & & & \\
\hline $\begin{array}{l}\text { Supervisor/manager expectations and actions } \\
\text { promoting safety }\end{array}$ & $a, b, c$ & $3.15(0.88)$ & $3.62(0.62)$ & $3.94(0.56)$ & & $3.87(0.60)$ & $3.85(0.60)$ & $3.86(0.61)$ \\
\hline $\begin{array}{l}\text { Organizational Learning-Continuous } \\
\text { Improvement }\end{array}$ & $a, b, c$ & $3.39(0.89)$ & $3.85(0.61)$ & $4.16(0.47)$ & $a, b$ & $4.07(0.54)$ & $4.10(0.52)$ & $4.13(0.55)$ \\
\hline Teamwork Within Hospital Units & $a, b, c$ & $3.64(0.92)$ & $3.96(0.62)$ & $4.26(0.49)$ & & $4.19(0.56)$ & $4.19(0.52)$ & $4.19(0.58)$ \\
\hline Communication Openness & $a, b, c$ & $2.59(0.94)$ & $3.01(0.83)$ & $3.46(0.80)$ & a & $3.40(0.83)$ & $3.31(0.83)$ & $3.35(0.86)$ \\
\hline Feedback and Communication About Errors & $a, b, c$ & $2.87(1.08)$ & $3.60(0.83)$ & $4.10(0.69)$ & $a, c$ & $3.98(0.78)$ & $3.97(0.75)$ & $4.03(0.76)$ \\
\hline Non-punitive Response to Error & $b, c$ & $2.38(0.84)$ & $2.44(0.73)$ & $2.69(0.74)$ & $a, b$ & $2.66(0.74)$ & $2.60(0.76)$ & $2.60(0.76)$ \\
\hline Staffing & $b, c$ & $2.72(0.62)$ & $2.80(0.55)$ & $2.93(0.55)$ & $a, b$ & $2.92(0.56)$ & $2.87(0.54)$ & $2.84(0.57)$ \\
\hline $\begin{array}{l}\text { Hospital Management Support for Patient } \\
\text { Safety }\end{array}$ & $a, b, c$ & $2.68(0.93)$ & $3.44(0.69)$ & $3.96(0.61)$ & $a, b$ & $3.88(0.69)$ & $3.80(0.67)$ & $3.74(0.78)$ \\
\hline Hospital Handoffs and Transitions & $a, b, c$ & $2.92(0.88)$ & $3.23(0.75)$ & $3.56(0.71)$ & $a, b$ & $3.51(0.71)$ & $3.47(0.74)$ & $3.36(0.80)$ \\
\hline Teamwork Across Hospital Units & $a, b, c$ & $2.69(0.85)$ & $3.20(0.67)$ & $3.63(0.63)$ & $a, b, c$ & $3.56(0.67)$ & $3.50(0.67)$ & $3.44(0.72)$ \\
\hline \multicolumn{4}{|c|}{$\begin{array}{l}\text { Patient Safety Grade } \\
\text { a. Significant difference between "Poor or Failing" and "Acceptable" } \\
\text { b. Significant difference between "Poor or Failing" and "Excellent/Nery Good" } \\
\text { c. Significant difference between "Acceptable" and "Excellent/Nery Good" }\end{array}$} & \multicolumn{5}{|c|}{$\begin{array}{l}\text { Number of Events Reported } \\
\text { a. Significant difference between "No events reported" and "1 to } 5 \\
\text { events reported" } \\
\text { b. Significant difference between "No events reported" and "> } 5 \\
\text { events reported" } \\
\text { c. Significant difference between "1 to } 5 \text { events reported" and "> } 5 \\
\text { events reported" }\end{array}$} \\
\hline
\end{tabular}

of patient safety, Feedback and communication about error, Communication openness, Frequency of events reported, Teamwork across hospital units, Staffing, Hospital handoffs and transitions, and Non-punitive response to error. Five dimensions deviated slightly from benchmark when comparing results to the US. When comparing results to Lebanon, four composites differed slightly from the benchmark and three when comparing results to KSA. However, none of the composites were found to be worse than US, Lebanon, or KSA (Table 6).

\section{Discussion}

This is the first major study addressing patient safety culture in public hospitals in Kuwait. Despite having some areas for improvement, public hospitals in Kuwait were found to have multiple areas of strength especially with unit-level dimensions. Some critical unit-level dimensions such as staffing, communication openness, and non-punitive response to error are highly determined by overall hospital culture and systems that enable action within these dimensions. Hospital management should work hard on addressing these issues to improve reporting, overall perception of patient safety and patient safety grade.

The composite on non-punitive response scored lowest which is consistent with findings in the region and across the world. This reflects a need to invest in system improvement initiatives and strengthen patient safety culture when trying to addressing medical errors. Hospitals that have poorly developed and ineffective policies cannot prevent errors and as a result, cannot improve reporting and ultimately impact patient safety [23]. Fear of punishment has been consistently found to reduce frequency of error reporting [24] and this is confirmed in regression findings.

The finding linking better events reporting with the composite on Management Support of Patient Safety supports evidence that links supervisory communication to improved patient safety culture. Engaging staff, discussing quality challenges, and collectively developing solutions gives employees ownership and pride in improving patient safety [25]. Findings clearly demonstrate the need to encourage health professionals to report more events given their impact in improving patient safety. The three major components of a positive patient safety culture are: a just culture, a reporting culture, and a learning culture [26]. Better reporting is highly dependent on having a nonpunitive environment where employees do not fear reporting events [5]. A punitive work environment is not a strange concept to hospitals in the region as it was reported to be an area for improvement in Lebanon and KSA $[15,16]$. 
Table 4 Generalized Estimating Equations

\begin{tabular}{|c|c|c|c|c|}
\hline \multirow{3}{*}{ Patient Safety Culture Composites } & \multicolumn{2}{|l|}{ Patient Safety Grade } & \multicolumn{2}{|c|}{ Number of Events Reported } \\
\hline & OR $(95 \% \mathrm{Cl})$ & \multirow[t]{2}{*}{$P$-value } & \multirow[t]{2}{*}{ OR $(95 \% \mathrm{Cl})$} & \multirow[t]{2}{*}{$P$-value } \\
\hline & & & & \\
\hline Supervisor/Manager Expectations \& Actions Promoting Patient Safety & $0.73(0.67-0.80)$ & $<0.001$ & $1.05(0.95-1.16)$ & 0.318 \\
\hline Organizational learning and Continuous Improvement & $0.65(0.55-0.77)$ & $<0.001$ & $1.27(1.16-1.39)$ & $<0.001$ \\
\hline Teamwork within units & $0.75(0.68-0.83)$ & $<0.001$ & $1.05(0.95-1.15)$ & 0.347 \\
\hline Communication Openness & $0.78(0.67-0.91)$ & 0.002 & $0.91(0.83-1.01)$ & 0.077 \\
\hline Feedback and Communications About Error & $0.72(0.63-0.83)$ & $<0.001$ & $1.10(1.02-1.19)$ & 0.018 \\
\hline Non-punitive Response to Error & $1.01(0.89-1.15)$ & 0.850 & $0.96(0.86-1.07)$ & 0.448 \\
\hline Staffing & $0.84(0.72-0.97)$ & 0.021 & $0.88(0.78-0.99)$ & 0.038 \\
\hline Hospital Management Support for Patient Safety & $0.47(0.40-0.54)$ & $<0.001$ & $0.81(0.71-0.92)$ & 0.002 \\
\hline Hospital Handoffs \& Transitions & $0.89(0.75-1.06)$ & 0.197 & $0.94(0.86-1.02)$ & 0.137 \\
\hline Teamwork Across Hospital Units & $0.81(0.67-0.98)$ & 0.027 & $0.94(0.82-1.07)$ & 0.318 \\
\hline \multicolumn{5}{|l|}{ Gender } \\
\hline Male & $1.11(0.90-1.35)$ & 0.300 & $1.14(0.97-1.35)$ & 0.122 \\
\hline Female & 1 & & 1 & \\
\hline \multicolumn{5}{|l|}{ Experience at the hospital } \\
\hline$<5$ years & $0.87(0.69-1.10)$ & 0.237 & $1.12(0.98-1.27)$ & 0.086 \\
\hline 5 to 20 years & $0.90(0.74-1.10)$ & 0.289 & $0.98(0.83-1.15)$ & 0.765 \\
\hline More or equal to 21 years & 1 & & 1 & \\
\hline \multicolumn{5}{|l|}{ Highest Degree } \\
\hline High school or below & $1.19(0.71-2.02)$ & 0.505 & $1.21(0.74-1.98)$ & 0.437 \\
\hline University Degree & $0.59(0.35-1.00)$ & 0.048 & $0.81(0.55-1.19)$ & 0.275 \\
\hline Technical Degree & $0.89(0.58-1.35)$ & 0.577 & $0.95(0.64-1.41)$ & 0.795 \\
\hline Other & 1 & & 1 & \\
\hline \multicolumn{5}{|l|}{ Position at the hospital } \\
\hline Physician & $1.15(0.86-1.53)$ & 0.344 & $0.57(0.47-0.69)$ & $<0.001$ \\
\hline Pharmacist & $1.12(0.69-1.83)$ & 0.637 & $0.52(0.32-0.82)$ & 0.005 \\
\hline Nurse & $0.97(0.73-1.29)$ & 0.829 & $0.51(0.43-0.59)$ & $<0.001$ \\
\hline Admin & $1.07(0.61-1.87)$ & 0.828 & $0.24(0.14-0.43)$ & $<0.001$ \\
\hline Other & 1 & & 1 & \\
\hline \multicolumn{5}{|l|}{ Nationality } \\
\hline Kuwaiti & $0.68(0.49-0.93)$ & 0.016 & $1.20(1.04-1.37)$ & 0.010 \\
\hline Non-Kuwaiti & 1 & & 1 & \\
\hline \multicolumn{5}{|l|}{ Interaction with patients } \\
\hline Yes & $1.01(0.76-1.32)$ & 0.967 & $0.82(0.68-0.98)$ & 0.033 \\
\hline No & 1 & & 1 & \\
\hline \multicolumn{5}{|l|}{ Hospital Size } \\
\hline Small & $1.65(1.17-2.33)$ & 0.004 & $2.67(2.17-3.30)$ & $<0.001$ \\
\hline Medium & $2.02(0.85-4.79)$ & 0.110 & $1.85(1.07-3.20)$ & 0.028 \\
\hline Large & 1 & & 1 & \\
\hline
\end{tabular}

The association between hospital size and patient safety culture outcomes is also of note. In particular, medium-sized and small-sized hospitals were found to have better reporting of events and better patient safety grade. This is consistent with research that states that large hospitals face challenges in the implementation of quality improvement initiatives because of bureaucracy while smaller hospitals with a more homogenous culture 
Table 5 Linear Mixed Model Regression

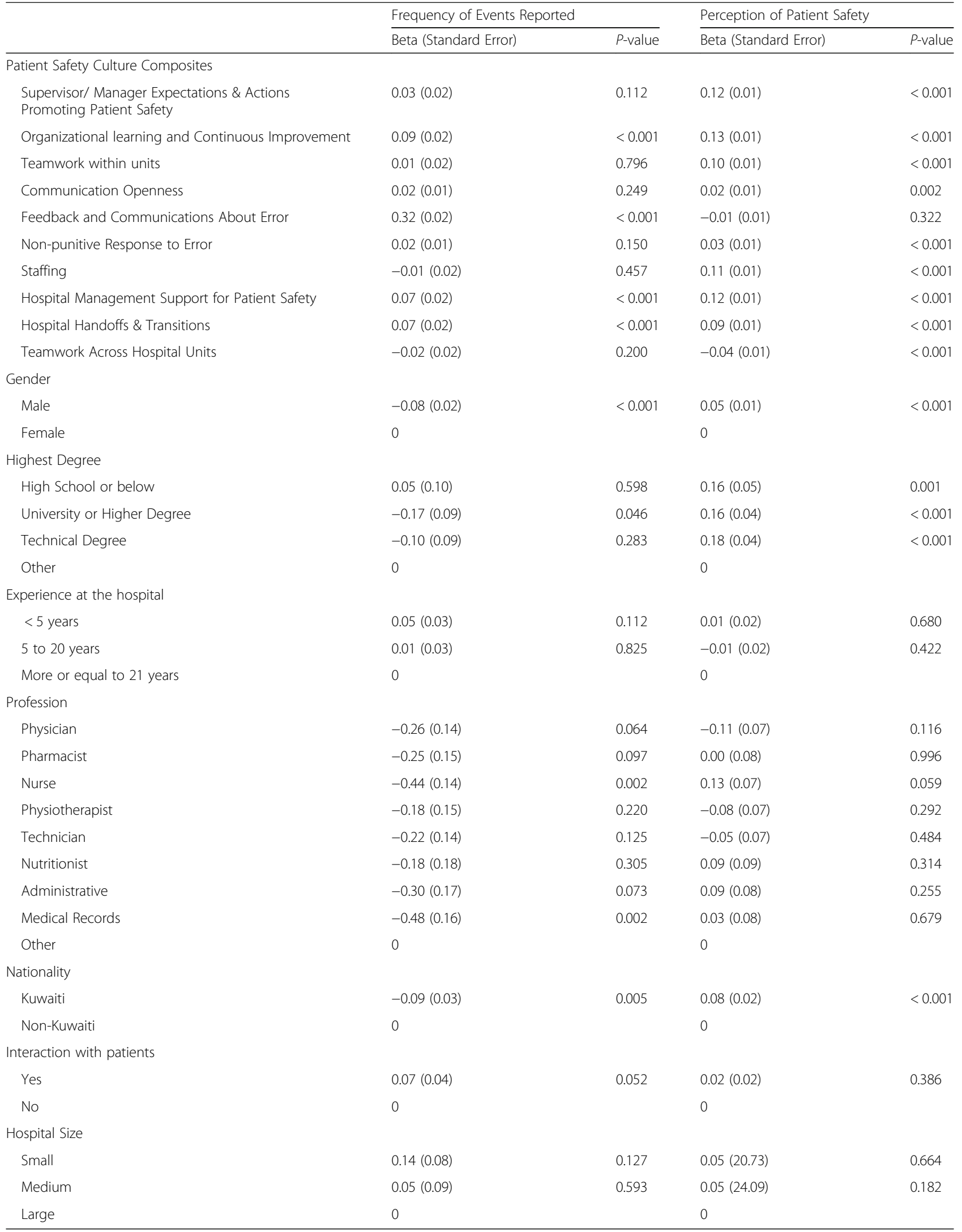


Table 6 Benchmarking Percent Positive on Survey Composites from Kuwait against those in US, Lebanon and KSA

\begin{tabular}{|c|c|c|c|c|c|c|c|}
\hline Composite & Kuwait & Benchmark US & & Benchmark Lebanon & & Benchmark KSA & \\
\hline Teamwork within units & $89.7 \%$ & $81 \%$ & $\nabla$ & $82.3 \%$ & $\nabla$ & $78.50 \%$ & $\square$ \\
\hline Supervisor/manager expectations and actions promoting patient safety & $77.0 \%$ & $76 \%$ & $\square$ & $66.4 \%$ & $\square$ & $60.60 \%$ & $\square$ \\
\hline Organizational learning-continuous improvement & $86.1 \%$ & $73 \%$ & $\square$ & $78.3 \%$ & $\square$ & $79.60 \%$ & $\square$ \\
\hline Management Support for Patient Safety & $77.7 \%$ & $72 \%$ & $\square$ & $78.4 \%$ & $\nabla$ & $71.40 \%$ & $\square$ \\
\hline Overall perception of patient safety & $60.5 \%$ & $66 \%$ & $\nabla$ & $72.5 \%$ & $\square$ & $58.20 \%$ & $\nabla$ \\
\hline Feedback and communication about error & $70.6 \%$ & $67 \%$ & $\square$ & $68.1 \%$ & $\square$ & $63.30 \%$ & $\square$ \\
\hline Communication openness & $47.2 \%$ & $62 \%$ & $\square$ & $57.3 \%$ & $\square$ & $42.90 \%$ & $\square$ \\
\hline Frequency of events reported & $58.8 \%$ & $66 \%$ & $\square$ & $68.2 \%$ & $\square$ & $59.40 \%$ & $\square$ \\
\hline Teamwork across hospital units & $63.8 \%$ & $61 \%$ & $\square$ & $56.0 \%$ & $\square$ & $61.60 \%$ & $\square$ \\
\hline Staffing & $39.6 \%$ & $55 \%$ & $\square$ & $36.8 \%$ & $\square$ & $35.10 \%$ & $\square$ \\
\hline Hospital handoffs and transitions & $61.9 \%$ & $47 \%$ & $\square$ & $49.7 \%$ & $\square$ & $51.50 \%$ & $\square$ \\
\hline Non-punitive response to error & $27.6 \%$ & $44 \%$ & $\square$ & $24.3 \%$ & $\square$ & $26.80 \%$ & $\square$ \\
\hline
\end{tabular}

$\square$ Meets or better than benchmark (results within $10 \%$ of benchmark)

$\square$ Deviates slightly from benchmark (results $10-50 \%$ from benchmark)

$\square$ Deviation from benchmark (results exceeding 50\% difference with benchmark)

are more likely to have staff members who share similar values [27].

Findings in this study showed that nurses are likely to report less events. This is critical as evidence in the literature indicate that nurses intercept $86 \%$ of potential errors [28]. Moreover, errors often go underreported for a multitude of reasons such as fear, humiliation, a punitive culture of reporting, or limited follow up after reporting an error [29].

Regression results indicate that employees who reported interaction with patients had fewer number of events and lower frequency of events reported. This is contrary to evidence in the literature which indicates that employees who have less interaction with patients are more at ease when reporting errors [30].

Benchmarking revealed many areas where Kuwaiti hospitals are performing at or better than benchmark and other areas of slight deviation. No major deviation from utilized benchmarks were observed. Comparing country findings to regional and international results can help hospital sets improvement goals and visualize their performance in comparison to others.

The main strength of this article lies in using a widely used and validated tool for assessing the culture of safety in hospitals at a national level. This study also utilized the Arabic version of the survey which was translated and validated in other Arab countries $[15,16,20]$. One limitation that should be highlighted is that nurses make up the majority of the sampled respondents. However, nurses comprise the majority of healthcare providers in most countries [31]. Despite having low representation from physicians, we were able to obtain input from a wide range of healthcare providers which can give a more comprehensive view on patient safety culture. Finally, the majority of respondents were nonKuwaitis. However, that reflects the demographic distribution of the country and not only hospitals.

\section{Conclusion}

This is the first large scale study that assesses patient safety culture in public hospitals in Kuwait. Improving patient safety culture is a critical if hospitals want to improve quality and safety of medical services. The overall culture within a hospital can reflect on the actions of hospitals with regard to safety and this can be revealed in patient outcomes. Study findings can guide and inform country level strategies to further improve the systems governing patient safety practices. Comparing findings to performance of other countries in the region can help hospitals and leaders visualize performance and set realistic targets for improvement. Investing in areas that affect overall patient safety culture, particularly event reporting, should be done if tangible improvement is to be made.

\section{Abbreviations \\ $\mathrm{Cl}$ : Confidence interval; HSOPSC: Hospital survey on patient safety culture; KSA: Kingdom of Saudi Arabia; OR: Odds ratio; PSC: Patient safety culture; SD: Standard deviation; US: United States \\ Acknowledgements \\ Authors would like to thank the Ministry of Health, State of Kuwait for funding this research. Authors would also like to thank the administrators of the participating governmental Health Care Organizations in Kuwait for facilitating this work. Special thanks go to all health professionals who participated in this national study. Thanks are also due to the data entry personnel for their efforts.}

Funding

No funding was provided for conducting this study. 


\section{Availability of data and materials}

Kindly contact the corresponding author for a copy of the dataset. Requests will be reviewed by the study team before they are sent.

\section{Authors' contributions}

HA, SZI, BAM, TAF, and FEJ contributed to the study design, manuscript development and review. HA, SZI, BAM, and TAF contributed to data collection and review. DJ contributed to data validation, data analysis and manuscript review. FE contributed to data analysis, manuscript development and review. All authors read and approved the final version of the manuscript.

\section{Ethics approval and consent to participate}

Ethical clearance to conduct the survey was provided by the Standing Committee for Coordination of Health and Medical Research in Kuwait. Informed consent was obtained from all survey participants.

\section{Consent for publication}

Not Applicable

\section{Competing interests}

The authors declare that they have no competing interests.

\section{Publisher's Note}

Springer Nature remains neutral with regard to jurisdictional claims in published maps and institutional affiliations.

\section{Author details}

${ }^{1}$ Ministry of Health, Kuwait City, Kuwait. 'Department of Health Management, Planning and Policy, High Institute of Public Health, Alexandria University, Alexandria, Egypt. ${ }^{3}$ Department of Health Management and Policy, Faculty of Heath Sciences, American University of Beirut, Beirut, Lebanon.

\section{Received: 2 June 2017 Accepted: 21 February 2018}

\section{Published online: 06 March 2018}

\section{References}

1. Singer $\mathrm{S}$, et al. Relationship of safety climate and safety performance in hospitals. Health Serv Res. 2009;44(2 Pt 1):399-421.

2. Kohn, LT, J. Corrigan, and MS Donaldson. To err is human: building a safer health system. 2000; Available from: https://www.ncbi.n/m.nih.gov/pubmed/ 25077248. Accessed 28 Feb 2018

3. Hellings J, et al. Challenging patient safety culture: survey results. Int J Health Care Qual Assur. 2007;20(7):620-32.

4. Deilkas ET, Hofoss D. Psychometric properties of the Norwegian version of the safety attitudes questionnaire (SAQ), generic version (short form 2006) BMC Health Serv Res. 2008:8:191.

5. Smits $M$, et al. Measuring patient safety culture: an assessment of the clustering of responses at unit level and hospital level. Qual Saf Health Care. 2009;18(4):292-6.

6. Blegen MA, et al. AHRQ's hospital survey on patient safety culture: psychometric analyses. J Patient Saf. 2009;5(3):139-44.

7. Quality, A.f.H.R.a. National Healthcare Quality and Disparities Report 2016 [cited 2016 7/5/2016]; Available from: https://nhqrnet.ahrq.gov/inhqrdr/. Accessed 28 Feb 2018

8. Viana De Lima Neto A, et al. Patient safety culture in health organizations: scoping review. Int Arch Med. 2017;10(74). https://doi.org/10.3823/2344.

9. Elmontsri $\mathrm{M}$, et al. Status of patient safety culture in Arab countries: a systematic review. 2017;7(2):e013487. https://doi.org/10.1136/bmjopen-2016-013487.

10. Danielsson $\mathrm{M}$, et al. A National Study of patient safety culture in hospitals in Sweden. J Patient Saf. 2017; https://doi.org/10.1097/PTS.0000000000000369

11. Mallouli $M$, et al. Assessing patient safety culture in Tunisian operating rooms: a multicenter study. Int J Qual Health Care. 2017;29(2):176-182. https://doi.org/10.1093/intqhc/mzw157.

12. Raeissi P, Reisi N, Nasiripour AA. Assessment of patient safety culture in Iranian academic hospitals: strengths and weaknesses. J Patient Saf. 2015;

13. Burlison JD, et al. A multilevel analysis of U.S. hospital patient safety culture relationships with perceptions of voluntary event reporting. J Patient Saf. 2016;

14. Zwijnenberg NC, et al. Healthcare professionals' views on feedback of a patient safety culture assessment. BMC Health Serv Res. 2016;16:199.
15. El-Jardali $F$, et al. The current state of patient safety culture in Lebanese hospitals: a study at baseline. Int J Qual Health Care. 2010;22(5):386-95.

16. El-Jardali $F$, et al. Patient safety culture in a large teaching hospital in Riyadh: baseline assessment, comparative analysis and opportunities for improvement. BMC Health Serv Res. 2014;14:122.

17. Sandars J, Cook G. ABC of patient safety. BMJ Books. 2009.

18. Smith SA, Yount N, Sorra J. Exploring relationships between hospital patient safety culture and consumer reports safety scores. BMC Health Serv Res. 2017;17(1):143.

19. Ghobashi MER, Mosleh H, Al-Doseri F. Assessment of Patient Safety Culture in Primary Health Care Settings in Kuwait. Epidemiol Biostat Public Health. 2014;11(3):9.

20. El-Jardali $F$, et al. Predictors and outcomes of patient safety culture in hospitals. BMC Health Serv Res. 2011;11:45.

21. Famolaro, T., et al., Hospital Survey on Patient Safety Culture 2016 User Comparative Database Report. 2016, [Agency for Healthcare Research and Quality][Rockville, MD].

22. Sorra J, et al. Hospital survey on patient safety. Culture. 2004; Available from: http://purl.access.gpo.gov/GPO/LPS83504. Accessed 28 Feb 2018.

23. Nieva, V.F. and J. Sorra, Safety culture assessment: a tool for improving patient safety in healthcare organizations. Qual Saf Health Care, 2003. 12 Suppl 2: p. ii17-23.

24. Child AP, et al. Keeping patients safe: transforming the work environment of nurses. 2004; Available from: http://public.eblib.com/choice/publicfullrecord. aspx?p=3564029. Accessed 28 Feb 2018.

25. Bradley $\mathrm{EH}$, et al. The roles of senior management in quality improvement efforts: what are the key components? J Healthc Manag 2003;48(1):15-28. discussion 29

26. Jha AK, et al. Summary of the evidence on patient safety: implications for research. Geneva: World Health Organization; 2008.

27. El-Jardali F. The impact of hospital rationalization and the interrelationships among organizational culture and nursing care processes on health related patient outcomes. Ottawa: National Library of Canada = Bibliothèque nationale du Canada; 2004

28. Leape $L L$, et al. The nature of adverse events in hospitalized patients. Results of the Harvard medical practice study II. N Engl J Med. 1991; 324(6):377-84.

29. VanGeest, J.B. and F. National Patient Safety, An educational needs assessment for improving patient safety: results of a national study of physicians and nurses. 2003, [Chicago, III.]: National Patient Safety Foundation.

30. Jones KSA, Xu L, Sun J, Mueller K. In: AHRQ, editor. The AHRQ hospital survey on patient safety culture: a tool to plan and evaluate patient safety programs, T.A.f.H.R.a.Q. Rockville: Agency for Healthcare Research and Quality U.S. Department of Health and Human Services; 2008.

31. Hughes RG. In: Hughes RG, editor. Tools and strategies for quality improvement and patient safety, in patient safety and quality: an evidencebased handbook for nurses. Rockville: Agency for Healthcare Research and Quality U.S. Department of Health and Human Services; 2008.

\section{Submit your next manuscript to BioMed Central and we will help you at every step:}

- We accept pre-submission inquiries

- Our selector tool helps you to find the most relevant journal

- We provide round the clock customer support

- Convenient online submission

- Thorough peer review

- Inclusion in PubMed and all major indexing services

- Maximum visibility for your research

Submit your manuscript at www.biomedcentral.com/submit
Biomed Central 